\title{
Anterior chamber depth during hemodialysis
}

This article was published in the following Dove Press journal:

Clinical Ophthalmology

9 August 2013

Number of times this article has been viewed

\section{Carolina Pelegrini Barbosa Gracitelli' \\ Francisco Rosa Stefanini' \\ Fernando Penha' \\ Miguel Ângelo Góes ${ }^{2}$ \\ Sérgio Antonio Draibe ${ }^{2}$ \\ Maria Eugênia Canziani ${ }^{2}$ \\ Augusto Paranhos Junior ${ }^{1}$ \\ 'Ophthalmology Department, ${ }^{2}$ Division of Nephrology, Federal University of São Paulo - UNIFESP, São Paulo, Brazil}

Background: Exacerbation of chronic glaucoma or acute glaucoma is occasionally observed in patients undergoing hemodialysis (HD) because of anterior chamber depth changes during this therapy.

Purpose: To evaluate anterior chamber depth and axial length in patients during HD sessions.

Methods: A total of 67 eyes of 35 patients were prospectively enrolled. Axial length and anterior chamber depth were measured using ultrasonic biometry, and these measures were evaluated at three different times during HD sessions. Body weight and blood pressure pre- and post-HD were also measured.

Results: There was no difference in the axial length between the three measurements $(P=0.241)$. We observed a significantly decreased anterior chamber depth $(P=0.002)$ during HD sessions.

Conclusion: Our results support the idea that there is a change in anterior chamber depth in HD sessions.

Keywords: anterior chamber, hemodialysis, axial length, acute angle-closure glaucoma

\section{Introduction}

Glaucoma is commonly present in patients with end-stage renal disease (ESRD) on hemodialysis (HD). Diabetes mellitus and age are major factors in this population. ${ }^{1}$

Exacerbation of chronic glaucoma or acute glaucoma during HD sessions is occasionally observed..$^{2-4}$ Primary angle-closure glaucoma results from a combination of predisposing anterior segment anatomy and unfavorable physiological behavior. ${ }^{5}$ Currently, it is defined as an occludable angle associated with trabecular meshwork damage/dysfunction (typically raised intraocular pressure [IOP] or presence of peripheral anterior synechiae) and structural and/or functional evidence of glaucomatous optic neuropathy. ${ }^{6}$ Although less common than the chronic form, the subacute and acute forms of angle closure may be the first manifestation of the disease. Reported anatomic risk factors for primary angle-closure glaucoma include short axial length, shallow anterior chamber, small corneal diameter, steep curvature, and thick, relatively anteriorly positioned lens. ${ }^{7-10}$

One of the most important biometric features predisposing to angle closure is a shallow anterior chamber. The depth of the anterior chamber depends on the position of the anterior lens surface and is determined by the thickness and position of the lens inside the eye. With aging, the lens usually grows, with an increase in the number of lens fibers, resulting in an increase in lens thickness and anterior curva- 
ture, so the anterior chamber becomes shallower with the increasing thickness of the anterior lens. ${ }^{11}$ In patients with glaucoma, with predisposed narrow angles, or eyes with impaired aqueous outflow, the possibility of acute IOP rise during HD could be much more frequent than in normal subjects. $^{12}$

The discussion about whether HD induces changes in intraocular pressure of nonglaucomatous eyes has been present since the sixth decade of the last century, ${ }^{2,12,13,14}$ and these changes have been shown to be harmful for those patients with glaucoma who are in HD programs. . $^{1,3,4}$

It was noticed in the Emergency Care Unit of Ophthalmology at the Federal University of São Paulo that some cases of acute angle-closure glaucoma had occurred after HD sessions. This fact makes ophthalmologic observation of patients in HD sessions essential. In this study, we aimed to investigate the change in axial length and anterior chamber depth in patients during HD sessions.

\section{Materials and methods}

This cross-sectional study adhered to the tenets of the Declaration of Helsinki and was approved by the Institutional Review Board of the Federal University of São Paulo. In addition, written informed consent was obtained from all participants.

\section{Patients}

We prospectively enrolled 67 eyes of 35 patients with ESRD treated with maintenance HD in the Kidney and Hypertension Hospital at the Federal University of São Paulo, Brazil. HD patients received dialysis therapy for at least 3 months and were dialyzed three times a week for 3-5 hours per session. All patients had arteriovenous fistulae and used a polysulfone hollow-fiber dialyzer (F8; Fresenius, Bad Homburg, Germany), and bicarbonate dialysate was used for all patients on dialysis sessions. The same methodology was used in our previous study. ${ }^{14}$

Exclusion criteria included, iridotomy, diagnosis of glaucoma or other ophthalmological disorders that might affect the evaluated parameters (myopia and hyperopia were not excluded), and patients with positive serological tests for HIV, hepatitis B virus, or hepatitis C virus. Complete ophthalmologic exams were performed. All patients underwent visual acuity measurements with a Snellen chart, biomicroscopic examination using slit lamp, fundoscopy, and IOP measurement.

IOP was measured using a Tono-Pen (XL Applanation Tonometer; Medtronic, Jacksonville, FL, USA), which is a portable electronic applanation device. Axial length and anterior chamber depth were measured using ultrasound biometry with an infrared system (Axis II, class II, type BF; Quantel Medical, Clermont-Ferrand, France). The ocular surface was anesthetized with $5 \mathrm{mg}$ proxymetacaine hydrochloride eye drops. It was requested that the eyes should be kept in the primary position focusing on a point opposite the patient and aligned to the ultrasound probe in order to obtain all the echoes (cornea, lens, and retina). Ten measurements were taken from each eye, and the acquisition of each echogram and its standard deviation were analyzed. Echograms that were not appropriate were excluded, with maximum standard deviation of $0.10 \mathrm{~mm}$.

The IOP, as well as axial length and anterior chamber depth, were measured at three different times during the HD session: at the beginning, 2 hours after initiation, and 4 hours after initiation. Systolic arterial pressure, diastolic arterial pressure, and body weight were also measured before and after HD.

\section{Statistical analysis}

Continuous variables were expressed as means \pm standard deviation (SD) or as a percentage. Comparisons between the systolic arterial pressure at the three time points during the HD session were evaluated using repeated-measures analyses of variance. IOP and biometrics features at the three time points were analyzed using generalized estimating equation models to account for the dependence between eyes of the same patient. SPSS 17.0 for Windows (IBM, Armonk, NY, USA) was used for statistical analysis. All probabilities ( $P$-values) were considered to be statistically significant if they were less than 0.05 .

\section{Results}

A total of 67 eyes of 35 patients were included. The mean age of the study patients was $49 \pm 17$ years $(65.7 \%$ male and $34.3 \%$ female). The predominant etiologies of ESRD were glomerulonephritis, diabetes mellitus, and hypertension (Table 1) average body weight and average arterial pressure are reported in Table 2 and Table 3, respectively. The average duration of HD treatment was $63 \pm 62$ months (range 1-288 months).

A significant anterior chamber depth variation (3.16 $\pm 0.06, P=0.002$ ) was found, but it did not show a significant variation for axial length $(23.51 \pm 0.19, P=0.241)$ during the HD process (Figures 1 and 2, respectively). Also, during HD, IOP did not significantly vary $(15.26 \pm 0.57$, $P=0.93$ ) (Figure 3). 
Table I Etiologies of end-stage renal disease (ESRD) at baseline $(\mathrm{n}=35)$

\begin{tabular}{ll}
\hline Etiology of ESRD & Number of participants \\
\hline Chronic glomerulonephritis & $13(37 \%)$ \\
Chronic interstitial nephritis & $8(23 \%)$ \\
Diabetes mellitus & $8(23 \%)$ \\
Hypertension & $3(8 \%)$ \\
Unknown & $3(8 \%)$ \\
\hline
\end{tabular}

\section{Discussion}

Several studies have been undertaken in order to prevent increase of IOP during the HD session. ${ }^{15,16}$ Some theories have been suggested. Previous studies proposed that IOP variation is related to a disorder of the drainage system. There is an increase in aqueous humor volume during the HD session, due to an alteration in plasma osmolarity, and deficient drainage would lead to an overload and higher levels of IOP. Nevertheless, this theory has not been clearly demonstrated. ${ }^{13,17,18}$ Recently, some studies have indicated that IOP increase is lower or even does not exist, probably due to improvement of HD techniques. ${ }^{12}$ Other studies have shown that IOP decreases during the HD process. ${ }^{15}$ This disagreement among results must be related to the different methods applied and the patient populations, such as age and ethnic group. In our study, we did not find variation in terms of IOP.

In the last 10 years, studies on this subject have focused on correlating IOP variation and HD. It is important, however, to evaluate not only the IOP but also the anterior chamber depth variation and its relation with IOP variation during the HD session, since patients with a narrow anterior chamber angle might be the ones who develop increased IOP and acute glaucoma due to reduction of anterior chamber depth. ${ }^{12}$ Rever et al reported that anterior chamber depth decreased significantly during acetate but not bicarbonate hemodialysis. ${ }^{19}$ The comparison between anterior chamber depth and IOP changes was not performed in that study. ${ }^{19}$ Costagliola et $\mathrm{al}^{20}$ did not find an association between IOP and anterior chamber depth. In our study, the anterior chamber depth decreased significantly after HD. Despite this result, IOP did not change. Probably, the changes in the anterior chamber would be important in extreme cases, eg, patients that already

Table 2 Average body weight during hemodialysis (HD)

\begin{tabular}{ll}
\hline Stage of hemodialysis & $\begin{array}{l}\text { Average body weight } \mathbf{( k g )} \\
(\boldsymbol{P}<\mathbf{0 . 0 0})\end{array}$ \\
\hline Before HD session & $64.5 \pm 16$ \\
Immediately after HD session & $64.1 \pm 16$ \\
\hline
\end{tabular}

Table 3 Average arterial pressure during hemodialysis (HD)

\begin{tabular}{ll}
\hline Stage of hemodialysis & $\begin{array}{l}\text { Average arterial pressure }(\mathbf{m m H g}) \\
(\boldsymbol{P}=\mathbf{0 . 1 6}), \text { minimum and maximum }\end{array}$ \\
\hline Before HD session & $136 \times 83(90-160 \times 60-100)$ \\
2 hours after HD initiation & $135 \times 81(100-180 \times 60-120)$ \\
4 hours after HD initiation & $131 \times 78(80-160 \times 50-110)$ \\
\hline
\end{tabular}

have a shallow anterior chamber and would be undergoing an HD session. In this case, IOP could change as well as the anterior chamber.

We used only bicarbonate dialysate for HD sessions of the patients included in our study, so the differences cannot be attributed to changes determined by changing the composition of the dialysate. The patients selected for this study were quite disciplined as regards fluid intake, because they showed variation in weight gain of around 4\% between HD sessions and consequently there was no need to undergo high rates of ultrafiltration in the HD session. Furthermore, the mean serum sodium concentration was $137 \mathrm{mEq} / \mathrm{L}$, while the sodium concentration in the dialysate was $138 \mathrm{mEq} / \mathrm{L}$ and the concentration of bicarbonate in the dialysate showed an average of $32 \mathrm{mEq} / \mathrm{L}$. However, these factors do not directly influence the anterior chamber depth variation in patients.

One possible explanation for the divergent results between the various studies conducted to observe changes in IOP can be explained by the kind of HD carried out, the use of dialysate with a variation in the concentration of sodium or acetate used in studies conducted by other researchers, ${ }^{21}$ and different methods used for measurement of the anterior chamber depth. Other parameters, such as gonioscopy, ${ }^{22}$ aqueous outflow facility, ${ }^{20}$ and visual field ${ }^{20}$ were not evaluated in this article. Other researchers observed that increase in osmotic

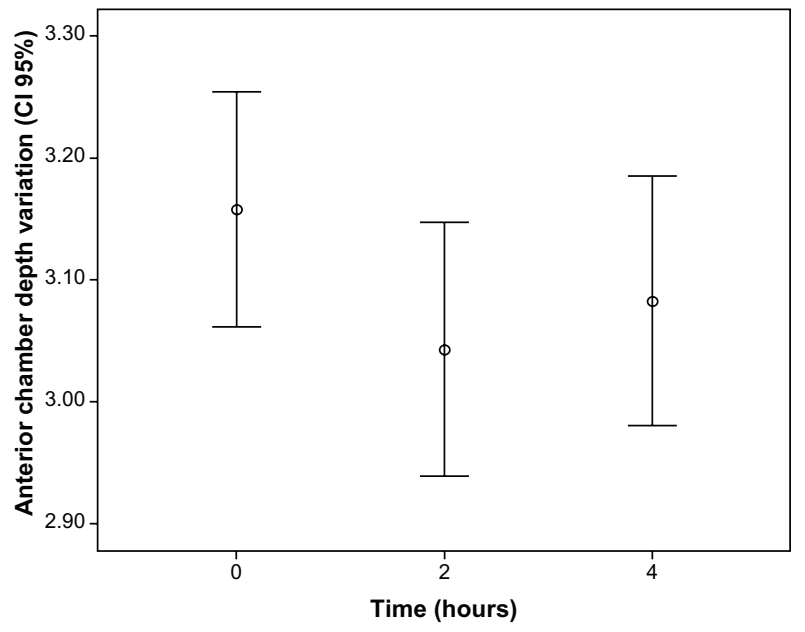

Figure I Anterior chamber depth variation during hemodialysis $(P=0.002)$. Abbreviation: $\mathrm{Cl}$, confidence interval. 


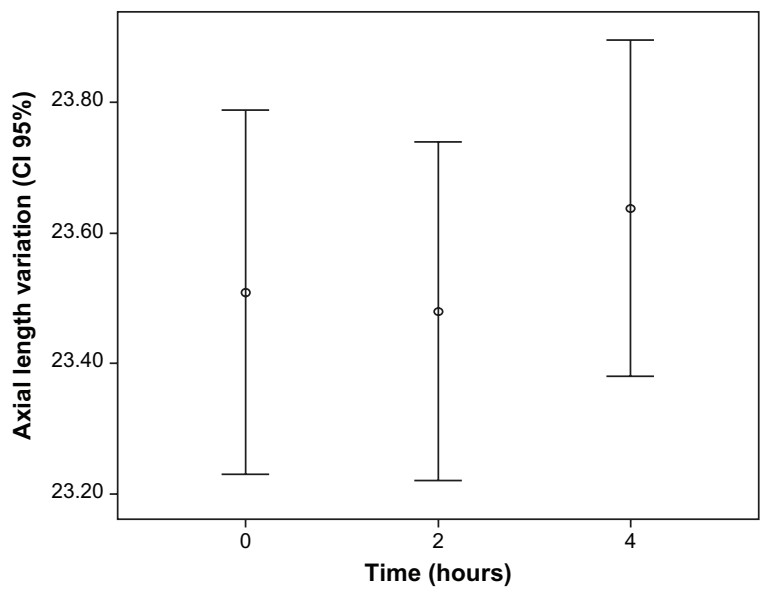

Figure 2 Axial length variation during hemodialysis. Abbreviation: $\mathrm{Cl}$, confidence interval.

pressure in the vitreous humor caused by the rapid removal of urea from blood by HD generates an osmotic disequilibrium between the plasma and the vitreous. ${ }^{20}$ Thus, it is plausible to think that in the affected angle, vitreous swelling can also cause further angle narrowing with forward pushing of the lens-iris diaphragm, and hence there is anterior chamber depth variation during HD sessions.

The main clinical implication of our findings is that the patient can have a pupillary block during HD or the progression can be noticed. As we know that glaucomatous optic nerves are more sensitive to large diurnal IOP fluctuations, theoretically, glaucomatous eyes of patients undergoing HD for years can suffer from damage. ${ }^{12}$ Older patients with advanced optic disk cupping or advanced visual field defects affecting the central field with split fixation could be at increased risk. ${ }^{12}$ Of course, new research can bring more information not only about IOP but also about anterior

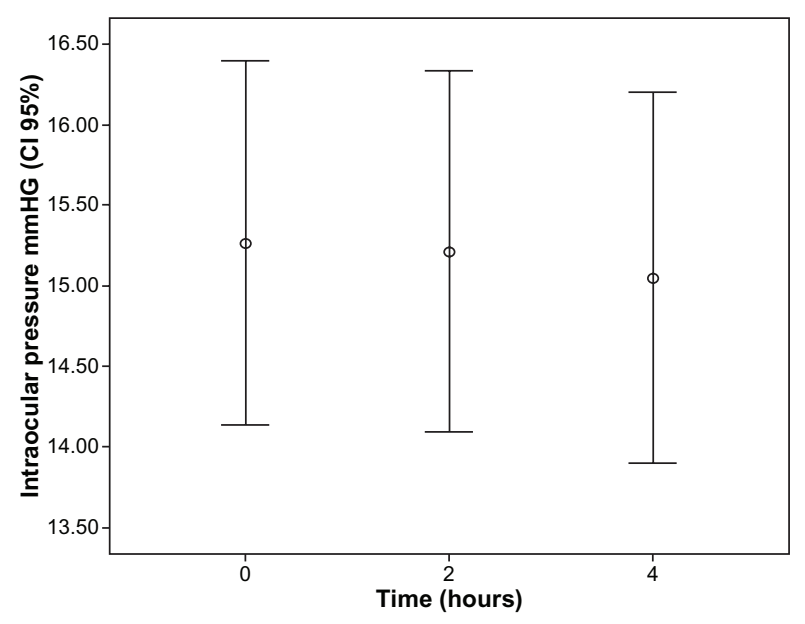

Figure 3 Variation in intraocular pressure during hemodialysis. Abbreviation: $\mathrm{Cl}$, confidence interval. chamber depth and axial length of the eye. The medical team treating the HD patient should be alert to possible ocular symptoms of acute IOP rise, such as blurred vision, eye pain, headache, or signs like dilated pupil and corneal edema, and consult the ophthalmologist in cases of suspected IOP increase.

Some specific characteristics of our study should be considered. First, our study is limited by its small sample size and low prevalence of narrow angles, which probably reflects the prevalence of narrow angles in Brazil. Thus, we do not know if a population with high narrow angle prevalence would strengthen the results. Second, we performed the measurements at three different times during the HD session: at the beginning, 2 hours after initiation, and 4 hours after initiation. Therefore, we do not know whether different measurement times during HD can produce different results. Third, we did not correlate the anterior chamber depth with the gonioscopy or with the visual field of the patient, so we cannot infer that these patients who had decreased anterior chamber depth also had narrow angle or not. Finally, there was no control group to show that the variation in anterior chamber depth was not due to other reasons than HD, eg, circadian rhythm.

In summary, our results support the idea that there is a narrowing anterior chamber depth in HD sessions. The hypothesis is that this change could be due to plasma osmolarity alterations. Therefore, all patients who are to undergo any HD session should be advised to see an ophthalmologist before the procedure to avoid the risk of having angle closure.

\section{Acknowledgments}

Thanks to Aurea Garibaldi, who helped us with a grammar review of the text.

\section{Disclosure}

The authors report no conflicts of interest in this work.

\section{References}

1. Tovbin D, Belfair N, Shapira S, et al. High postdialysis urea rebound can predict intradialytic increase in intraocular pressure in dialysis patients with lowered intradialytic hemoconcentration. Nephron. 2002;90(2):181-187.

2. Sitprija V, Holmes JH, Ellis PP. Intraocular pressure changes during artificial kidney therapy. Arch Ophthalmol. 1964;72:626-631.

3. Choong YF, Menage MJ. Symptomatic acute raised IOP following hemodialysis in a patient with end stage renal failure. Br J Ophthalmol. 1998;82(11):1342.

4. Tokuyama T, Ikeda T, Sato K. Effect of plasma colloid osmotic pressure on intraocular pressure during haemodialysis. Br J Ophthalmol. 1998;82(7):751-753.

5. Day AC, Baio G, Gazzard G, et al. The prevalence of primary angle closure glaucoma in European derived populations: a systematic review. Br J Ophthalmol. 2012;96(9):1162-1167. 
6. Foster PJ, Buhrmann R, Quigley HA, Johnson GJ. The definition and classification of glaucoma in prevalence surveys. Br J Ophthalmol. 2002;86(2):238-242.

7. Tarongoy P, Ho CL, Walton DS. Angle-closure glaucoma: the role of the lens in the pathogenesis, prevention, and treatment. Surv Ophthalmol. 2009;54(2):211-225.

8. Lowe RF. A history of primary angle closure glaucoma. Surv Ophthalmol. 1995;40(2):163-170.

9. Nongpiur ME, Ku JY, Aung T. Angle closure glaucoma: a mechanistic review. Curr Opin Ophthalmol. 2011;22(2):96-101.

10. Alsbirk PH. Limbal and axial chamber depth variations. A population study in Eskimos. Acta Ophthalmol (Copenh). 1986;64(6): 593-600.

11. George R, Paul PG, Baskaran M, et al. Ocular biometry in occludable angles and angle closure glaucoma: a population based survey. $\mathrm{Br} J$ Ophthalmol. 2003;87(4):399-402.

12. Levy J, Tovbin D, Lifshitz T, Zlotnik M, Tessler Z. Intraocular pressure during haemodialysis: a review. Eye (Lond). 2005;19(12): 1249-1256.

13. Lee DA, Brubaker RF, Ilstrup DM. Anterior chamber dimensions in patients with narrow angles and angle-closure glaucoma. Arch Ophthalmol. 1984;102(1):46-50.
14. Barbosa CP, Stefanini FR, Penha F, et al. A. Intraocular pressure and ocular perfusion during hemodialysis. Arq Bras Oftalmol. 2011; 4(2):106-109.

15. Doshiro A, Ban Y, Kobayashi L, Yoshida Y, Uchiyama H. Intraocular pressure change during hemodialysis. Am J Ophthalmol. 2006;142(2): 337-339.

16. Dujić M, Jovanović D, Marković P. Rise in intraocular pressure during dialysis. Clin Nephrol. 1995;44(5):348.

17. Tomlinson A, Leighton DA. Ocular dimensions in the heredity of angleclosure glaucoma. Br J Ophthalmol. 1973;57(7):475-486.

18. Clark BA, Lowe RF. Alignment of eye and slitlamp beam. Ophthalmologica. 1973;166(3):194-198.

19. Rever B, Fox L, Bar-Khayim Y, Nissenson A. Adverse ocular effects of acetate hemodialysis. Am J Nephrol. 1983;3(4):199-204.

20. Costagliola C, Mastropasqua L. The influence of hemodialysis on intraocular pressure: III. Aqueous humor dynamics and tissue hydration. Ann Ophthalmol. 1991;23(1):31-34.

21. Cecchin E, De Marchi S, Tesio F. Intraocular pressure and hemodialysis. Nephron. 1986;43(1):73-74.

22. Jaeger P, Morisod L, Wauters JP, Faggioni R. Prevention of glaucoma during hemodialysis by mannitol and acetazolamide. $N$ Engl J Med. 1980;303(12):702.
Clinical Ophthalmology

\section{Publish your work in this journal}

Clinical Ophthalmology is an international, peer-reviewed journal covering all subspecialties within ophthalmology. Key topics include: Optometry; Visual science; Pharmacology and drug therapy in eye diseases; Basic Sciences; Primary and Secondary eye care; Patient Safety and Quality of Care Improvements. This journal is indexed on

Submit your manuscript here: http://www.dovepress.com/clinical-ophthalmology-journal

\section{Dovepress}

PubMed Central and CAS, and is the official journal of The Society of Clinical Ophthalmology (SCO). The manuscript management system is completely online and includes a very quick and fair peer-review system, which is all easy to use. Visit http://www.dovepress.com/ testimonials.php to read real quotes from published authors. 